\section{Images in}

\section{Cardiovascular Disease}

Check for updates

\title{
Triple Vessel Coronary Cameral Fistula: A Rare Case of Angina
}

\section{OPEN ACCESS}

Received: Nov 25, 2019

Accepted: Dec 1, 2019

\section{Address for Correspondence:}

Deepak Agrawal, MD

Department of Cardiology, Jaipur

HeartInstitute, Jaipur Hospital, Lal Kothi, Near

S.M.S. Stadium, Tonk Road, Jaipur (Rajasthan), India Pin; 302015.

E-mail: drdeepakagrawal1984@gmail.com

Copyright (C) 2020 Korean Society of Echocardiography

This is an Open Access article distributed under the terms of the Creative Commons Attribution Non-Commercial License (https:// creativecommons.org/licenses/by-nc/4.0/) which permits unrestricted non-commercial use, distribution, and reproduction in any medium, provided the original work is properly cited.

\section{ORCID iDs}

Deepak Agrawal (D)

https://orcid.org/0000-0002-2448-2687 Ashok Garg (iD

https://orcid.org/0000-0001-9991-0538 G L Sharma (iD

https://orcid.org/0000-0002-3710-4511

\section{Conflict of Interest}

The authors have no financial conflicts of interest.

\author{
Deepak Agrawal $\mathbb{D}^{-}, \mathrm{MD}^{1}$, Ashok Garg $\mathbb{D}^{-}, \mathrm{MD}^{2}$, and G L Sharma $\mathbb{D}^{\circ}, \mathrm{MD}^{1}$ \\ 'Department of Cardiology, Jaipur Heart Institute, Jaipur, India \\ ${ }^{2}$ Department of Preventive and Non-Invasive Cardiology, Jaipur Heart Institute, Jaipur, India
}

A 68-year-old female came to our hospital with exertional chest pain, fatigue, and breathlessness on exertion since the last 3-4 months. On physical examination, her blood pressure was 150/70 $\mathrm{mmHg}$, and her heart rate was 96 beats/min. Electrocardiography showed sinus rhythm and no specific changes in the ST segment or the T wave.

Echocardiography revealed ventricles of normal size and function with no regional wall motion abnormality. Coronary angiography revealed multiple fistulae that arose from all threemajor coronary arteries (left anterior descending, left circumflex, andright coronary arteries) thatdrained into the left ventricle near the apex (Figure 1, 2, 3 \& Movie 1, 2, 3). The coronary arteries were free of any atherosclerotic disease. The patient was discharged from the hospital on optimal medical management including beta blockers and a antihypertensive with instructions for diabetescontrol.

Coronary-cameral fistulae are a rare anomaly. They are predominantly congenital communications between the coronary arterial circulation and the chambers or great vessels

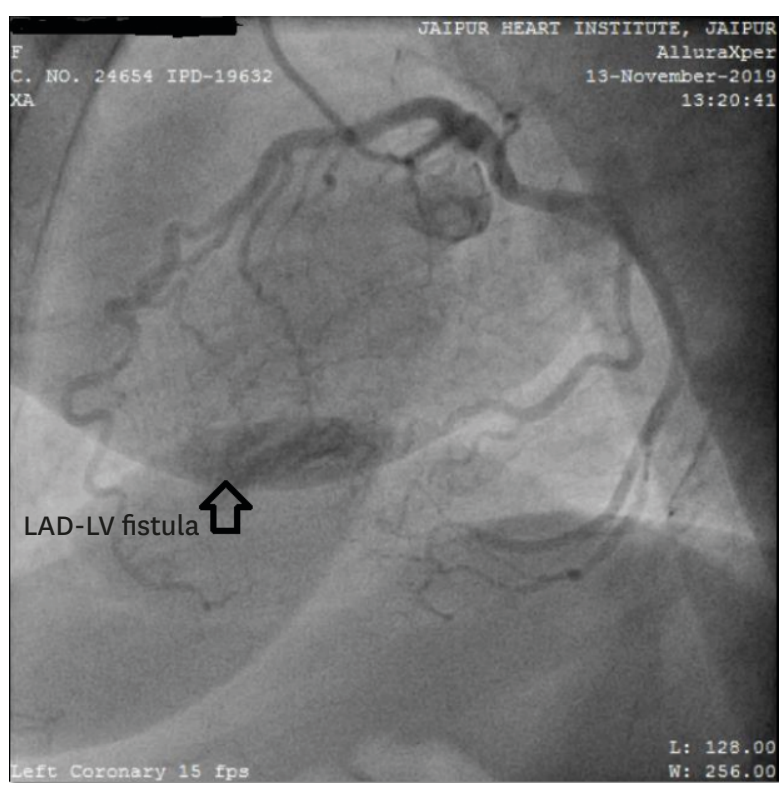

Figure 1. Coronary angiographic projection showing a coronary cameral fistula arising from the left anterior descending artery and draining into the left ventricle. 


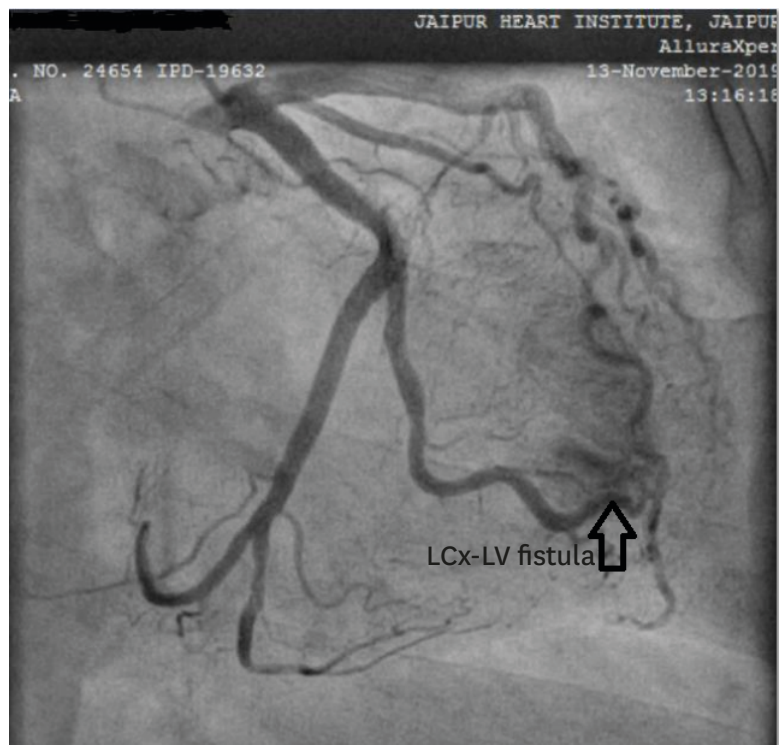

Figure 2. Coronary angiographic projection showing a coronary cameral fistula arising from the left circumflex artery and draining into the left ventricle.

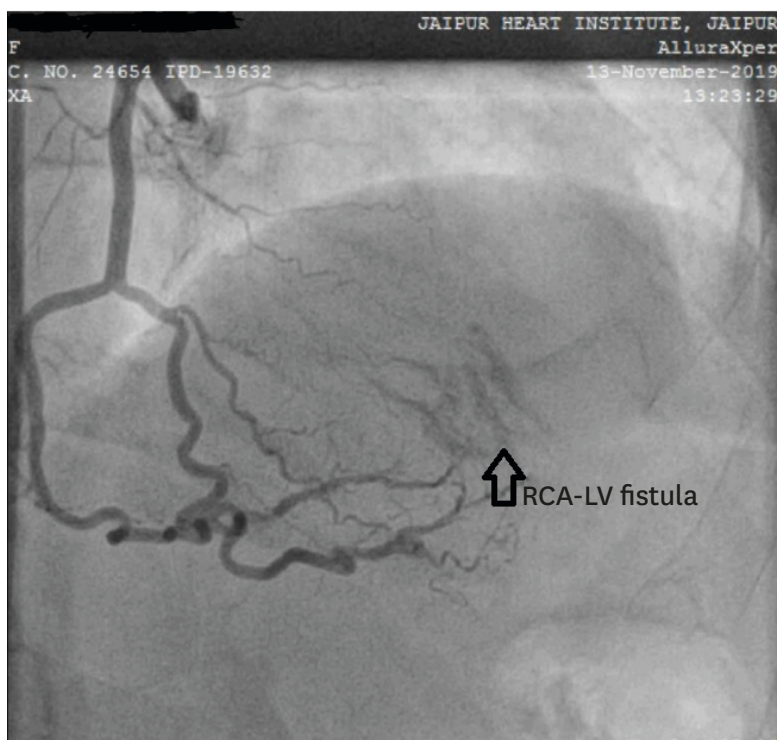

Figure 3. Coronary angiographic projection showing a coronary cameral fistula arising from the right coronary artery and draining into the left ventricle.

of the heart. It is rare that a coronary artery fistula causes myocardial ischemia. Therapeutic approaches are designed to reduce myocardial oxygen demand and thereby ameliorate the demand-supply mismatch.

Coronary arteriography is the best method to determine the origin and drainage of such fistulae; indeed, in our patient, this method showed multiple coronary artery fistulae. 


\section{SUPPLEMENTARY MATERIALS}

\section{Movie 1}

Coronary angiographic projection showing a coronary cameral fistula arising from the left anterior descending artery and draining into the left ventricle.

Click here to view

\section{Movie 2}

Coronary angiographic projection showing a coronary cameral fistula arising from theleft circumflex artery and draining into the left ventricle.

\section{Click here to view}

Movie 3

Coronary angiographic projection showing a coronary cameral fistula arising from the right coronary artery and draining into the left ventricle.

Click here to view 